\title{
Dissent in the Midst of Emotional Territory ${ }^{1}$
}

\section{LINDA CAROZZA York University}

\begin{abstract}
This paper focuses on disagreement spaces fused with emotion. Following Gilbert's emotional mode of argumentation (1997), further expansions of the mode are made here, specifically for the purposes of being able to classify different types of emotional arguments. First, general concerns with arguments that stray from the traditional approach are addressed. Then a classification system for different types of emotional arguments is developed. Some of the criteria that help determine emotional arguments include dialogue types, arguers involved, as well as the use of emotion.
\end{abstract}

Résumé: Cet article concentre sur le fusionnement des émotions et des espaces de désaccord. On suit le mode émotif d'argumentation de Gilbert (1997), et on le développe spécifiquement dans le but d'être capable de classer différents types d'arguments émotifs. On s'intéresse premièrement aux arguments qui s'éloignent de l'approche traditionnelle. Ensuite on présente un système de classification de différents types d'arguments émotifs. Certains critères de cette classification incluent les types de dialogues, les personnes impliquées dans ces arguments, ainsi que l'usage des émotions.

Keywords: argument dialogue, argument goals, emotion, emotional argument, multi-modal argumentation, practitioner, social style model, traditional argumentation

\section{Introduction}

That emotions play a role in argumentation is an idea contested by probably very few argumentation theorists. However, recognizing that emotions play a role in argumentation and further acknowledging emotional arguments as credible arguments in their own right are very different admissions. This paper focuses on emotional argumentation primarily in terms of interaction or interpersonal disagreement spaces. The existing literature on emotional arguments is scant, though there are theorists within the field who write about its legitimacy or future development. Emotional arguments should be studied, according to Dale Hample, "because arguing is a motivated human activity, reasoning always has an emotional element" (2005, p. 128). However, Michael A. Gilbert notes a particular trend has presided within the field of argumentation: "certain very human factors such as emotion and intuition have been viewed as extraneous to proper argumentation and solely the domain of other disciplines (Psychology and Communication Theory) or, even worse, the concern of sophists and manipulators" (1997a, p. 26). In response to this typical view of arguments that are primarily emotional, in addition to acknowledging that emotional arguments are inherent in most argumentative contexts, I quote Douglas Walton who writes that, "emotional appeals can be 
reasonable arguments in some cases" (1992, p. 255). Devoting a book to the place of emotion within arguments, Walton shows how emotions in arguments can be fallacious but also how they can be helpful to the overall goals of a particular argument.

Focusing on emotions as functional aspects of argumentation, this paper is divided into two main parts. First I recapitulate existing theory on emotional arguments, focusing on Gilbert's emotional mode (1997a), and then more briefly on Ben-Ze'ev $(1995,1996)$ and Plantin (1999), who provide cognitive and linguistic approaches respectively to emotion in argument. Stemming from Gilbert's work, I then begin a preliminary descriptive account of a more advanced notion of emotional argumentation than currently exists. This includes further defining emotional arguments and explaining their presence in critical discussions, debates, negotiations, and quarrels, four different argumentative dialogues outlined by Walton (1990). This account is by no means complete but rather should be thought of as a beginning to the vast nature of emotional argumentation. Before concluding, I introduce a tool for dispute resolution practitioners, the social style model (Furlong 2005), which can help argumentation practitioners better understand and navigate emotional arguments. Whether practitioners are analysts performing empirical studies of emotional arguments, professionals who deal with arguments continually as part and parcel to their work, or any individual who confronts emotional arguments, this work is ultimately aimed at providing insight and tools to help them with the emotional mode of argumentation.

\section{Existing literature on emotional arguments}

\subsection{Risks of studying emotional argumentation}

Depending on how emotion in argumentation is studied by an analyst, there run different risks, of which Hample mentions at least three. A third party observing argumentative communication can interfere with the natural flow of the emotions of the arguers. Second, if equipment is used to study the physiology of emotions during argumentation, it can be rather intrusive. Finally, post-argument interviews can be contaminated by the interviewer's questions (2005, p. 143). While these are important challenges to acknowledge in the study of emotional argument, riskpreventative measures can be worked on and worked out. Plus, the more traditional mode of argument may run some of the same risks as well as others. For instance, the first concern is that having an analyst present while an argumentative exchange takes place runs the risk of influencing the arguers, perhaps by having them suppress their emotions or maybe even exaggerate them. An analyst does not even have to be present - a video recorder can be recording the interaction and the arguments can still be influenced. In any case, the naturalness of the emotions can be affected, hindering the natural argument. The main issue here is that a third party to the emotional argument upsets the flow of the argument, possibly changing its original form. This could be a risk in any mode of argumentation where there is an analyst 
present. The reasons could be altered as well (not just the emotions), whether they end up being suppressed, exaggerated, made-up, and so on because there is an observer. Here too, there could just be a simple recorder in the room for the purposes of compiling a transcript of the interaction, and reasoning could be influenced.

In cases of the more traditional conception of argument with third party analysts, an analyst typically studies the strength of the reasons as justification or refutation of views. Analogous to this, emotional argumentation analysts can do the samestudy the use, strength, or justificatory purposes of emotion. Whatever the argument occurring, alterations can always be made, conscious or not, because of the presence of a third party. Once understood and acknowledged, the same process of argument location and maybe evaluation can begin to take place with emotional arguments that have been in place with traditional arguments for years. The real difference for analysts of traditional and emotional arguments is that the former already has a general theory associated with it, while the latter is still quite unexplored territory.

\subsection{The emotional mode of argumentation according to Gilbert}

In Coalescent Argumentation (1997a) Gilbert introduces the multi-modal model of argumentation, which includes four modes of argumentation. Developed, in essence, to address real people in real argumentative situations the four modes are the logical, the emotional, the visceral, and the kisceral, where the latter three modes are considered additions to the first more traditional mode of argument, what Gilbert calls the critical-logical tradition. The emotional mode is the only one I draw on in this project, though the kisceral and visceral modes are not entirely unconnected to the basic foundations that guide it. Each of these three modes presents alternatives to the traditional critical-logical mode. Gilbert stresses that what they offer is a taxonomy of argumentative communication-in other words, one can question what mode gives any argument its strength (1997a, p. 79). Important to keep in mind is that multi-modal argumentation deems that arguments can have each mode present at any time, and often do, though there is one mode that is more emphasized. For instance, "a good emotional reason might be a poor logical or kisceral reason” (1997a, p. 83).

According to Gilbert emotions can be present in arguments as reasons, emotional grounds, or as a means of expressing arguments. In emotional arguments the strength of the argument comes primarily from its emotional content (1997a, p. 83). Emotional arguments better communicate human aspects of arguments that might otherwise be ignored, yet important to the argument in terms of structure, delivery, and reception. They could indicate an arguer's degree of commitment to her claim, or how genuine an arguer is in presenting her argument. These directly link to the listeners receiving arguments_-noting the above criteria could influence how a listener accepts, questions, or rejects claims made. Emotional arguments, according to Gilbert, "include such elements as degree of commitment, depth, and 
the extent of feeling, sincerity, and degree of resistance" (1997a, p. 84). Thus an emotionally-involved arguer could add credibility or strength to the argument.

Consider Marco and Lee, who have been business partners for the last five years. Marco does not agree with Lee's latest argument about starting to hire professional accountants to take care of their financial business matters, but Marco also sees that Lee is not that committed to the idea, as Lee stated it casually and began talking about other matters. In this situation there is no obvious degree of commitment or strength to the idea, and so Marco does not feel obligated to address it. If Lee had instead stated that the two of them really need to consider hiring someone who knows the ins and outs of accounting, perhaps becoming excitable - or more intense about the idea because Lee anticipates there might be hesitation from Marco-then Marco, seeing a deeper level of commitment and seriousness, would likely engage in further argumentative dialogue and exploration regarding the hire. An analogy I want to specifically point out here is that Lee could have advocated the hire with a number of well-thought out reasons based on research, but Lee instead becomes more excitable and aggressive about the idea. In either case, we should have tools to at least map out the argument and possibly analyze its strength. This exists for more traditional approaches to argument; the reasons could be evaluated for their acceptability, relevance, and overall sufficiency (Johnson and Blair 2006). But there are no means to work with the situation above; for some models or theories of argumentation actually, Lee might not even be making an argument.

\subsection{Other conceptions of emotional arguments}

Gilbert's mode of emotional arguments is what motivates this project. What it lacks in its generality is technical rigour, and whether or not a model of emotional argument needs such is still a question. Here I quickly introduce two authors who have a more detailed, and stricter, sense of emotional arguments.

In "Emotions and argumentation" (1995) Aaron Ben-Ze'ev asserts (1) that emotions do constitute a particular kind of argumentation; (2) emotions are rational; and, (3) emotions can constitute efficient argumentation. For Ben-Ze'ev an emotional argument is specifically one which has emotion(s) used as reason(s) for a claim or action-a notion of emotional argument that coincides with Gilbert's mode. Taking it to a different level than Gilbert though, Ben-Ze'ev's psychologicallyinformed position deems that there are four aspects inherent in an emotion within emotional argumentation. An emotion has cognitive, evaluative, motivational, and feeling aspects (Ben-Ze'ev 1995, p. 190). Each of these is required for an emotional argument to have occurred, and they can be considered different aspects of a single state (Ben-Ze'ev 1996, p. 237).

Referring to the example between Lee and Marco above, imagine the two had been going back and forth in their deliberation regarding hiring a professional accountant to take over the small business accounting matters they had been working 
through themselves since the inception of the business. Lee would much rather hire someone now that their business is slowly growing and they are not aware of the entire accounting system, its ins and outs. Marco thinks they have been handling matters fairly well, and until there are serious problems they come against in their accounting measures, why bother paying someone to do what they have been doing? These are the arguments verbalized by the pair, and they seemingly both make sense, or at least one is not drastically stronger than the other. Now, in continuing their argumentative discussion about hiring a professional accountant, Lee decides not to do anymore of the accounting; either they hire someone or Marco can take care of it alone if he really wants. Thinking this is a drastic decision, Marco questions Lee, and Lee responds that he does not understand the accounting cycle like Marco anyway. It frustrates Lee that no matter how hard he tries Marco usually has the solutions.

This has now become an emotional argument according to Ben-Ze'ev. The cognitive aspect involves Lee's awareness of Marco's accounting skills. Recognizing that Lee's skills are not as advanced as Marco's, perhaps even inferior, is the evaluative aspect. The motivational aspect prompts Lee to remove the circumstances that make Lee feel frustrated with accounting, less competent, thus hiring someone so that Lee and Marco are not left doing the accounting activities. And, lastly, the feeling element involves Lee's frustration at always coming second to Marco, thus feeling inferior. For Ben-Ze'ev emotions constitute arguments when they are the reason for some claim or action. Thinking of Lee's feelings of inferiority, as an emotional state of frustration, prompts his proposals for action (either an accountant is hired, or Marco takes on the accounting alone; either way, Lee is not putting himself in the situation that makes him feel inferior).

For Ben-Ze'ev, emotional arguments are common, practical situations, associated with active arguers, occurring in the context of interpersonal situations. Consequently, emotional arguments are rational in the sense that they are functional, associated and coinciding with the given context (1996, p. 193). And, they are efficient in the messages they send-their persuasive power tends to be strong (1996, p. 197). Ben-Ze'ev thus provides a psychologically-informed account of emotions in emotional arguments, where emotions act solely as reasons.

Christian Plantin, in "Arguing emotions" (1999), states that emotions have cognitive components because they are linked with language associations, and people react differently to emotions. Thus, like Ben-Ze'ev Plantin has a psychological approach to the subject of emotional argumentation. Unlike Ben-Ze'ev though, Plantin does not focus just on the emotion. Rather, the emotional dimensions of argument can be investigated by recognizing "emotional sentences," those sentences that tell us that someone is experiencing an emotion, and by locating the "experiencer," the subject experiencing the emotion, plus the "emotion terms," which are the societal labels that get attached to emotions (Plantin 1999, pp. 5-7). His theory relies on emotions that are declared in the context of argumentation, and not on inner states that one cannot be sure about. And, different from Ben- 
Ze'ev, Plantin focuses on emotions as claims.

When Lee asserts that he will never understand accounting like Marco, and it is frustrating for him to do any accounting at all alongside Marco, Lee is the experiencer of the emotion, frustration. Once the experiencer and the emotion are determined, one is ready to construct the context that prompted the emotion, according to Plantin.

\subsection{Types of emotional arguments summarized}

Gilbert states that emotions can be used as reasons within arguments, as well as means of expressing an argument. Ben-Ze'ev gives a detailed conception of the emotion in the former context, where emotion functions as a reason for a claim. In other words, Ben-Ze'ev gives an account of what exactly constitutes emotion. Plantin looks at arguments where emotions make up the claim and he reconstructs the situation to determine the reasons leading to the claim. This gives us three different ways that emotion can play out in argumentation, and they all represent the position of the arguer who expresses reasons and claims. I add two more to them, already introduced in Carozza (2002), prompted by Walton's work (1992) on the ad misericordiam and ad baculum. In an ad misericordiam an arguer appeals to the emotions of her listeners, specifically pity and sympathy for others, so that an action or claim will be accepted based on appealing to those types of empathic emotions (Walton 1992, p. 259). In an ad baculum an arguer evokes emotions of fear from her listeners; this involves stirring up feelings of threat, terror, or anxiety that otherwise would not have been triggered (1992, p. 259). These last two means of emotional argument represent the response of the listener in argumentation; thus, while the former three focus on the arguer's use of emotion, the latter two represent the listeners' emotional response to an argument. While this is not an exhaustive list, and it should be further developed with the help of empirical research, it is a start to thinking of the different ways that emotion plays a part in argumentation. I summarize with a list of the ways emotional arguments can occur:

(i) Emotions can be used to express arguments (Gilbert 1997).

(ii) Emotions can be used as grounds for a claim (Ben-Ze'ev 1995; Gilbert 1997).

(iii) Emotions can make up a claim (Plantin 1999).

(iv) Empathic emotions of the audience can be appealed to (Walton 1992).

(v) Emotions of fear in an audience can be evoked (Walton 1992).

\section{Dissent in the midst of emotional territory}

I turn now to articulating the definitions of argument and emotion that ground this approach, and then I show how emotions function in arguments in terms of fulfilling a particular argument dialogue's goals (see Walton 1990). This at least should demonstrate the functional aspects of emotional arguments. 
The motivation for developing such an account at all stems from a concern with the practical implications of theory. Considering emotions in argumentation theory brings along negative and positive attributes. To begin with the negative, there is so much more to be aware of as argumentation analysts, with very little theory to ground it all, and sometimes this criterion is not wholly familiar to us or obvious based on individual life experiences, exposure, cultures, and so on. The positive attributes, however, far outweigh the negative. Recognizing the role of emotion in argumentative discourse provides more context or details that would otherwise be construed as fallacious or peripheral to the core argument. The emotion that situates an argument provides a "big picture" effect, allowing different contextually relevant analyses of a given argumentative interaction, and it balances the focus between the argument itself and its arguers. In the end, the purpose of articulating this approach at all is for the benefit of those who deal with emotional arguments on a daily basis: lawyers, judges, arbitrators, mediators, counselors, psychologists, friends, parents, etc. We all come across emotional arguments, some professionally and some more personally, and yet an expanded theory that first explains and then gives tools to deal with these arguments does not really exist.

\subsection{Definitions of argument, emotion, and emotional argument}

The notion of argument I work with comes from mainly two theorists. First, Gilbert writes, "an argument is any disagreement-from the most polite discussion to the loudest brawl" (1996, p. 5). And, Daniel J. O'Keefe states that an argument ${ }_{2}$ involves interaction of some sort, thus referring to the process of arguing (1982, p. 4). Considered together, an argument is some sort of interaction where there is disagreement between parties. This notion of argument necessarily requires more than one party, in order to have incompatible views that prompt disagreement. As well, there needs to be interaction regarding the incompatible views. Other than that, the communicative interaction that occurs (critical discussion, negotiation, quarrel, etc.), the mode of argument that occurs (logical, emotional, etc.), and so on, can all vary, provided there are at least two parties who communicate about their dissenting views in some capacity.

In dealing with the "emotional" aspects of argument, I avoid overly philosophical or psychological definitions of the term, mostly because this project is aimed at any individual in the process of recognizing, mapping, analyzing, handling, facilitating, and/or solving emotional arguments. The cognitive or physiological aspects of emotion, for instance, are not that significant in the understanding of emotional argumentation. What is important to note about emotion is that it is part and parcel to the social sphere. Alison M. Jaggar writes that emotions are:

... wrongly seen as necessarily passive or involuntary responses to the world. Rather, they are ways in which we engage actively and even construct the world. They have both 'mental' and 'physical' aspects, each of which 
conditions the other; in some respects they are chosen but in others they are involuntary; they presuppose language and a social order (1989, p. 159).

Emotion then is a state or feeling we have, voluntarily or involuntarily, consciously or unconsciously. It is what we do with emotion that is integral to argumentation. Our state or feelings can prompt particular delivery or expressions of arguments; they can be part of the structure of arguments; or, we might try and prompt particular states or feelings from our listeners. In all cases we should be aware of the context surrounding the emotion, who demonstrates the emotion, how the emotion is received by others, and the cultural environment, personal experiences, and social context that surround the emotion. Because emotions are part of the social sphere, we have an intuitive connection with them. Antonio Damasio (1994) has a similar notion of our connection with emotion-we feel the right responses and act accordingly in a given situation, and at the same time we tend to know when we implement the wrong responses.

An emotional argument is a very common occurrence. As humans we are susceptible to both feeling and disagreeing or arguing. When a disagreement occurs between parties, their emotions can be involved in a number of ways. What follows is a first attempt at demonstrating ways that emotions are part of particular argumentation dialogues.

\subsection{A descriptive account of emotional arguments using Grice and Walton}

A concern often voiced about emotional arguments is their lack of containment. It is difficult to know them, let alone address them; they do not follow any standard form-they come and go on whim, as they are fluid. While this might be the situation some arguers find themselves in, let's say in a nasty quarrel, by and large emotions do not create a whirlwind of confusion and uncertainty. In dealing with emotional arguments as analysts, Paul Grice's maxims of communication in "Logic and Conversation" (1975) are a useful guide. For Grice conversation is cooperative, and as participants of conversation you should "make your conversational contribution such as is required, at the stage at which it occurs by the accepted purpose or direction of the talk exchange in which you are engaged" (1975, p. 26). This is the cooperative principle and there are maxims that accompany it-I highlight them here for the purposes of transferring them to emotional arguments only.

Argumentative interactions ideally should abide by the following maxims: arguers should speak to the topic, contributions neither being too little or too much; arguers should be as clear as possible; arguers' contribution should be relevant to the topic; arguers should not say anything they are not sure of or believe is false (1975, p. 28). An important point Grice makes about these maxims, only briefly stated here, is that in conversation we sometimes fail to abide by the rules. For emotional arguments, we can consider these all relevant communication rules to adhere to, and the flouting of any could be cause for further investigation in the context of emotional arguments (emotional fallacies or motivation of emotional 
arguments, for instance). When these guidelines are roughly followed in an emotional argument, they could provide for good communicative interaction and not chaotic emotional arguments. Grounding emotional arguments in Grice's cooperative principle of conversation demonstrates that emotional arguments can occur in productive communicative spaces.

In "What is reasoning? What is argument?" (1990), Walton outlines eight types of argumentative dialogues. Considering the goals of four dialogues in particular, I begin to map out how emotion can play a productive role in the argument process by connecting the dialogues with the above five ways emotion can be a part of arguments.

In a critical discussion, the goal of each party is to convince the other (Walton 1990, p. 413). So, each arguer is justifying her own view and/or refuting the other party's view in order to come to a better understanding of the issues at hand and to ultimately resolve the conflict of opinion. In such a context using emotions as reasons could contribute to the argumentative process. As well, to a degree, emotional expression can help move the dialogue along. Of the four dialogues addressed here, a critical discussion is least likely to include all types of emotional argument or even a high degree of emotional argumentation generally. This is due to its emphasis on rational discussion as outlined by the Pragma-Dialectical model (van Emeren and Grootendorst 2004). In fact, in a later work, Walton writes: " "critical discussion' is defined as a subtype and especially idealized model of the persuasion dialogue" (1998, p. 48). The rules governing critical discussions make it difficult to stray from the traditional notion of argumentation without violating a preset rule and committing a fallacy, and so emotional reasons and expressions can only play a small part in them.

In a debate, the goal of each party is to persuade a third party (Walton 1990, p. 413). Here debates can be thought of in the formal context and even informally, where two friends, for instance, might be arguing with each other with a third neutral friend who is expected to decide the better position. Similar to a critical discussion, though a more adversarial context, debates could also include emotional arguments where emotions are reasons or used as a means of expression. In this context, the means of expression can be a bit more extreme than a critical discussion, as debates can be more intense because of the more adversarial atmosphere. As well, using emotion to appeal to a third party's pity or evoke fear in a third party are possibilities. For instance, one party might try to cast doubt on the other party's views, possibly scaring a third party into changing her mind with some newfound data. Any type of emotional argument is possible in the context of a debate, whereas with a critical discussion there is at least some responsibility to better understand the situation, and not just persuade some third party.

In a negotiation, the parties involved aim to maximize their gains (1990, p. 413). Parties have different interests and need to come to some sort of settlement, ideally where both parties leave the negotiation with something. Slightly different from Walton's notion of negotiation, yet still retaining the same goals, this is not a 
win-lose context as bargaining tends to be, but rather a win-win situation (see Fisher and Ury 1991 for interest-based negotiation). In a negotiation, parties can make use of almost any type of emotional argument to meet some of their own interests. Using emotion to express the importance of the issue, using emotions as reasons for wanting something, evoking pity or fear to alter the other party's interests are all means to parties moving from their opposing interests to a middleground of consensual agreement.

In a quarrel, parties' goals are to lash out verbally (Walton 1990, p. 413). Inherent in a quarrel is emotion, simply because it is almost always what prompts a quarrel, a dialogue more emotionally elevated than the others mentioned. In a quarrel parties mainly benefit from venting their emotions, and this can take place via any emotional means at the party's disposal-the most obvious being expressing one's emotions. Unlike the three dialogues above, quarrels might have emotions as their claim as well. Something as simple as "I am angry with you" could be the issue for a party in a quarrel, whereas this is not likely in any of the other dialogues. Quarrels are the most personal, and so emotions are commonplace.

By connecting the different types of emotional argument with some of Walton's argument dialogues, and specifically the goals of each dialogue, we have a picture of the different ways emotions play out in argumentation. Sometimes emotions do not enter into a critical discussion, or a negotiation that turns to primarily bargaining for the right "price" for example, but sometimes they are important to the arguers and the context, and this is when we need to be able to understand their effects on the argument process instead of bracketing the emotion as extraneous to the dialogue.

The question that arises from work like this is: how do we evaluate emotional arguments? Maybe once a full representation of emotional arguments is developed, that could be tackled. For my concerns here, as long as the maxims of conversation are roughly followed, and emotion occurs in any of the ways above, we have an emotional argument. Instead of judging its credibility I want to turn to further understanding how the emotional argument functions. To do this, understanding the parties involved is crucial. Thus far I have touched on different ways emotion can be part of argumentation, and how they function in different dialogues-I turn now to focus on the actual arguers who bring emotion to the dialogues.

\section{The Social Style model as a functional means for practitioners of argument}

Emotions come from people, and one of the reasons emotional arguments are not accepted into mainstream argumentation is their tendency to be relative to individuals. Two arguers can react quite differently to the same action or statement, for instance. If we have better tools for understanding the personalities behind emotional arguments, we could understand how to deal with the argumentative circumstances as practitioners. Delineated by Gary T. Furlong, one of the tools available to a mediator is the "social style model" (2005). Developed in line with the MyersBriggs Personality Type Indicator, the social style model focuses on the 
externalizations of personality, which means that a third party can diagnose a party's social style without asking her personality questions per se. From a practitioner's point of view, this is a functional approach to assessing personality types during conflict resolution. And, since this is a discourse space where emotional arguments can run rampant, the social style model can help practitioners, or even parties themselves, recognize and work with the predominant style in another party during the exchange of arguments. Important to keep in mind is that this approach is based on generalizations and is not an exact science.

There are two types of behaviour to determine. The first concerns assertiveness: is an individual "ask" or "tell" assertive? By observing her behaviour a third party must determine whether an individual is more reserved, keeping thoughts to herself-this is ask assertive; or whether an individual is more direct and forceful in interaction - a tell assertive stance. And, the second behaviour deals with responsiveness; is a speaker controlled or emotive? If she tends to be distant and formal, focusing on tasks and not feelings, then she is control responsive. And, if she is generally animated, displaying emotions and/or recognizing them in others, then she is emote responsive (Furlong 2005, pp. 193-195). After assessing an individual from these two criteria, one can more or less diagnose a social style that an individual is predominantly. The behaviour styles are as follows (2005, p. 195):

Each of the styles has a list of typical characteristics. An analytical person is task-oriented, focuses on details, is a careful decision-maker, and logical. A driver is a fast-paced, independent, task-oriented, dominating individual. An amiable individual is dependable, relationship-centered, supportive, and avoids confrontation. Finally, an expressive is animated, energetic, fast-paced, and opinionated (2005, pp. 196-197). Once these criteria of arguers in interaction are known, assessing the emotional arguments in terms of their causes or possible roadblocks they present to the conversation as a whole is possible. People with different social styles tend not to approach communication in the same manner, let alone emotional communication. Thus, one arguer's emotional argument might not jibe with her

$\begin{array}{lll}\begin{array}{l}\text { ANALYTICAL } \\ \text { Ask Assertive } \\ \text { and } \\ \text { Control Responsive }\end{array} & \begin{array}{l}\text { DRIVING } \\ \text { Tell Assertive } \\ \text { and } \\ \text { Control Responsive }\end{array} \\ \begin{array}{ll}\text { AMIABLE Assertive } \\ \text { Ask Assertive } \\ \text { and } \\ \text { Emote Responsive }\end{array} & \begin{array}{l}\text { EXPRESSIVE } \\ \text { Tell Assertive } \\ \text { and } \\ \text { Emote Responsive }\end{array} \\ \text { Emote Responsive }\end{array}$


listener simply because her listener does not orient in the same manner, and consequently does not really give much credit or acknowledgement to the emotional argument.

There are different style adjustments that one can make to better suit her conversational partner. The one important for emotions in particular surrounds "facts and feelings" (2005, p. 203). Should one deal more or less with facts or with feelings? Typically, emote responsive individuals, amiables and expressives, will make more use of feelings in their conversations, while drivers and analyticals are more concerned with facts. From a third party perspective, being able to diagnose social styles can indicate one's natural tendency in communication. Thus, amiables and expressives might make more emotional arguments than directives and analyticals. Furthermore, this might happen in ordinary circumstances and not highly "emotional" ones either. This is just to emphasize that emotional arguments do not have to be chaotic or loud communicative events; giving emotional reasons or being more expressive are average occurrences, especially for amiables and expressives.

When amiables and/or expressives come together in argumentative communication, there could be more emotional arguments than a typical conversation. If the situation is a highly volatile one the arguments could even impede communication. This is where a practitioner could intervene in the process. On the other hand, if analyticals and directives come together to discuss the same matter, the arguments will be different, maybe even void of obvious emotion. What this shows is that understanding the arguer is important to getting an understanding of the arguments that get communicated, and having a standard of what types of argument are acceptable winds up prejudicing social styles. A trickier situation arises when there is some combination of an amiable or expressive with a directive or analytical. When this occurs in conflict resolution settings, a mediator might translate one party's message into another party's communication style which provides for a better understanding of the issues typically (2005, pp. 206-207). If this were to occur around arguments in general, for instance an expressive becomes more emotional in relaying her argument, while the other party remains "rational" and fact-driven, a third party could interpret the idea behind the emotional expressive and relay it to the more fact-driven party in a manner that would be understood, comfortable, and possibly accepted. This requires pulling out the enthymematic parts of arguments in conversation, whether they be in emotionally or logically styled arguments.

Further study on this topic should address how to coalesce different arguing patterns of arguers in a single interaction and how to translate one means of argument language to another. Having concrete measures to deal with these can provide for smoother communication with resolutions that parties can come to agree on. As well, though it is not the focus in this paper, the social style model shows that all social types have typical back-up reactions used in modes of crisis. Argumentative 
situations could be perplexing spaces for some, and so back-up styles might be acted on while arguing. As practitioners to argumentative situations, knowing social indicators of back-up behaviours can help parties come to agreement as well.

\section{Conclusion}

Emotional arguments, especially when expressed naturally and genuinely, need serious address. Refraining from the endeavour for fear of fallacious content is a concern set up by traditional argumentation, but it need not be the case. There is no question that emotions used to purposely manipulate a situation can be obvious violations of proper argumentation. However, as Walton writes, "emotion should not be (categorically) opposed to reason, even though appeals to emotion can go wrong or be exploited in some cases" (1992, p. 257). Whether emotional arguments are good ones is neither here nor there for this project specifically. It is, rather, a subject for future study and already initiated by Gilbert (1997b). Before full normative notions of emotional arguments can be tackled, a thorough descriptive model still needs to be developed. Something to keep in mind is that there is a spectrum of emotion at play in any communicative act, simply because we are human. Gilbert writes: "Communication will be more or less emotional running from nearly pure emotional states to ones that are hardly emotional at all" (1997a, p. 84). It makes sense to at least begin mapping out what the more emotional states of arguing look like.

This paper has put forth a descriptive account of emotional argumentation. Bringing together the notions of Gilbert (1997), Ben-Ze'ev (1995, 1996), and Plantin (1999) gives at least five types of emotional argumentation to start. Depending on the dialogue - while four were mentioned in this paper, there are more to investigateemotional arguments can function to achieve particular goals of the discourse. And, finally, even with definitions, conversational rules, dialogues, and goals considered, truly understanding emotional arguments requires an understanding of the arguers. To address this last point, I referred to a tool available to dispute resolution practitioners. Adapted, the social style model (Furlong 2005) can help make sense of emotional arguers and their arguments, but more than that: it brings together different styles of arguing so that agreement can occur between parties in disagreement. $^{2}$

\section{Notes}

${ }^{1}$ This article was one of two that received the J. Anthony Blair prize for an outstanding paper by a graduate student presented at the OSSA 2007 conference. - The Editors

${ }^{2}$ I wish to thank Lisa Calce for taking the time to discuss and edit the ideas in this paper.

\section{References}

Ben-Ze'ev, A. (1995). Emotions and argumentation. Informal Logic, 17(2), 189-200. 
Ben-Ze'ev, A. (1996). Typical emotions. In O. D. Kitchener (Ed.), Psychology and Philosophy. London: Sage.

Carozza, L. (2002). Traditional argumentation broadened. Unpublished master's thesis, University of Windsor, Windsor ON, Canada.

Damasio, A. (1994). Descartes' error. New York: G.P. Putnam.

Eemeren, F. H. van and R. Grootendorst. (2004). A systematic theory of argumentation: The pragma-dialectical approach. Cambridge: Cambridge University Press.

Fisher, R., and W. Ury. (1991). Getting to yes: Negotiating agreement without giving in. New York: Penguin Books.

Furlong, G. T. (2005). The conflict resolution toolbox: Models and maps for analyzing, diagnosing, and resolving conflict. Mississauga, ON: Wiley.

Gilbert, M. A. (1996). How to win an argument (2nd ed.). New York: Wiley.

Gilbert, M. A. (1997a). Coalescent argumentation. Mahwah, NJ: Lawrence Erlbaum Associates.

Gilbert, M. A. (1997b). Prolegomenon to a pragmatics of emotion. Paper presented at the Ontario Society for the Study of Argumentation Conference: Argumentation and Rhetoric, Brock University, St. Catherines.

Grice, P. H. (1975). Logic and Conversation. Syntax \& Semantics, 3, 23-40.

Hample, D. (2005). Arguing: Exchanging reasons face to face. New Jersey: Lawrence Erlbaum Associates, Publishers.

Jagger, A. M. (1989). Love and knowledge: Emotion in feminist epistemology. Inquiry, 32(2), 151-176.

Johnson, R. H., \& J. A. Blair (2006). Logical self-defense. New York: International Debate Education Association.

O'Keefe, D. J. (1982). The concepts of argument and arguing. In R. J. Cox, \& Willard, C. A. (Ed.), Advances in argumentation theory and research (pp. 3-23). Illinois: Southern Illinois Press.

Plantin, C. (1999). Arguing emotions. Paper presented at the Fourth International Conference of the International Society for the Study of Argumentation, Amsterdam.

Walton, D. (1990). What is reasoning? What is argument? Journal of Philosophy, LXXXVII, 399-419.

Walton, D. (1992). The place of emotion in argument. University Park, PA: Pennsylvania State University Press.

Walton, D. (1998). The new dialectic: Conversational contexts of argument. Toronto: University of Toronto Press.

Linda Caorozza Department of Philosophy

York University

Toronto ON

Canada M3J $1 P 3$

Lcarozza@yorku.ca 